\title{
Right Posterior Segmental Hepatic Duct: Role of Intraoperative Cholangiogram to Prevent Extrahepatic Biliary Duct Injuries
}

\author{
Ikhwan $\mathrm{SM}^{\mathrm{a}}$, Hairol $\mathrm{O}^{\mathrm{b}}$, Razman $\mathrm{J}^{\mathrm{b}}$, Zamri $\mathrm{Z}^{\mathrm{b}}$, Affirul $\mathrm{C}^{\mathrm{c}}$ \\ ${ }^{a d D e p a r t m e n t ~ o f ~ S u r g e r y, ~ U n i v e r s i t i ~ S a i n s ~ M a l a y s i a, ~ K u b a n g ~ K e r i a n, ~ K e l a n t a n ~}$ \\ ${ }^{b}$ Hepatobiliary Unit, Department of Surgery, Universiti Kebangsaan Malaysia, Cheras, Kuala Lumpur \\ c Department of Surgery, Universiti Sains Islam Malaysia, Nilai, Negeri Sembilan
}

\begin{abstract}
Extrahepatic bile ducts constitute a significant anatomic site for surgeons when performing hepatobiliary operations from minor procedure such as cholecystectomy to major operation such as hepatectomy. The challenges for surgeon in performing such cases increase when congenital variance of biliary tree occurs which may lead to unintentional bile duct injuries. We reported a case of a lady who presented with obstructive jaundice secondary to huge distal common bile duct stone. The presence of right posterior segmental hepatic duct, which rarely occurs, was discovered during intraoperative cholangiogram before common bile duct exploration. The operation was successful without incidence of biliary duct injury.
\end{abstract}

Keywords: Extrahepatic biliary tract; cystohepatic junction; right posterior segmental duct

\section{INTRODUCTION}

The normal extrahepatic biliary tract is formed by the right and left hepatic ducts, which join together to form the common hepatic duct. The cystic duct drains to the common hepatic duct from its lateral position. The common bile duct is formed after the cystohepatic junction which drains into the second part of duodenum. The incidence of congenital anomalies of extra hepatic biliary tract varies from 0.58 to $47.2 \%$ depends on type and location of the biliary ducts. ${ }^{1}$ Smajda and Blumgart's classification of the biliary tract anatomic variations is the first classification used where they divide the anomalies into six main anatomic types. ${ }^{2}$ The other classification was described by Yoshida where the variants were classified into 7 types. ${ }^{3}$ The presence of right posterior segmental duct in which the cystic duct drains into it is one of the uncommon variants discovered in human.

\section{CASE REPORT}

A 47-year-old woman was admitted to hepatobiliary ward due to obstructive jaundice. Physical examination

Corresponding author

Ikhwan Sani Mohamad, MD, MMed (Surgery ) USM

Department of Surgery

Universiti Sains Malaysia,

16150 Kubang Kerian, Kelantan

Tel: 017-9278535

Email: ikhwansani@yahoo.com.my revealed tenderness at right hypochondriac region without evidence of cholangitis. The liver function test showed high conjugated bilirubin with raised alkaline phosphatase. Ultrasound was done showed dilated common bile duct of $12 \mathrm{~mm}$ with presence of distal common bile duct stone of $10 \mathrm{~mm}$ size.

She was prepared for operation after failure of endoscopic removal of the stone. The operative procedures planned for her was laparascopic cholecystectomy, intraoperative cholangiography and common bile duct exploration. The initial procedure of cholecystectomy was challenging since there was dense adhesion after the Hartmann's pouch. Intraoperative cholangiography was later performed and revealed presence of extrahepatic right posterior segmental duct (Figure 1). The cystic duct drained directly into this accessory duct. The cystic duct was ligated and transfixed with absorbable suture and the gallbladder was safely removed without ductal injury. The common bile duct was further explored and the stone was successfully thrawled out by using balloon cathether. Post procedure cholangiogram showed smooth contrast flow inside common bile duct to the duodenum. T- Tube was inserted at the end of procedure.

T-tube cholangiography at day 10 revealed smooth flowing contrast without evindence of retained stone or bile leak. She was safely discharged home without major complication. 


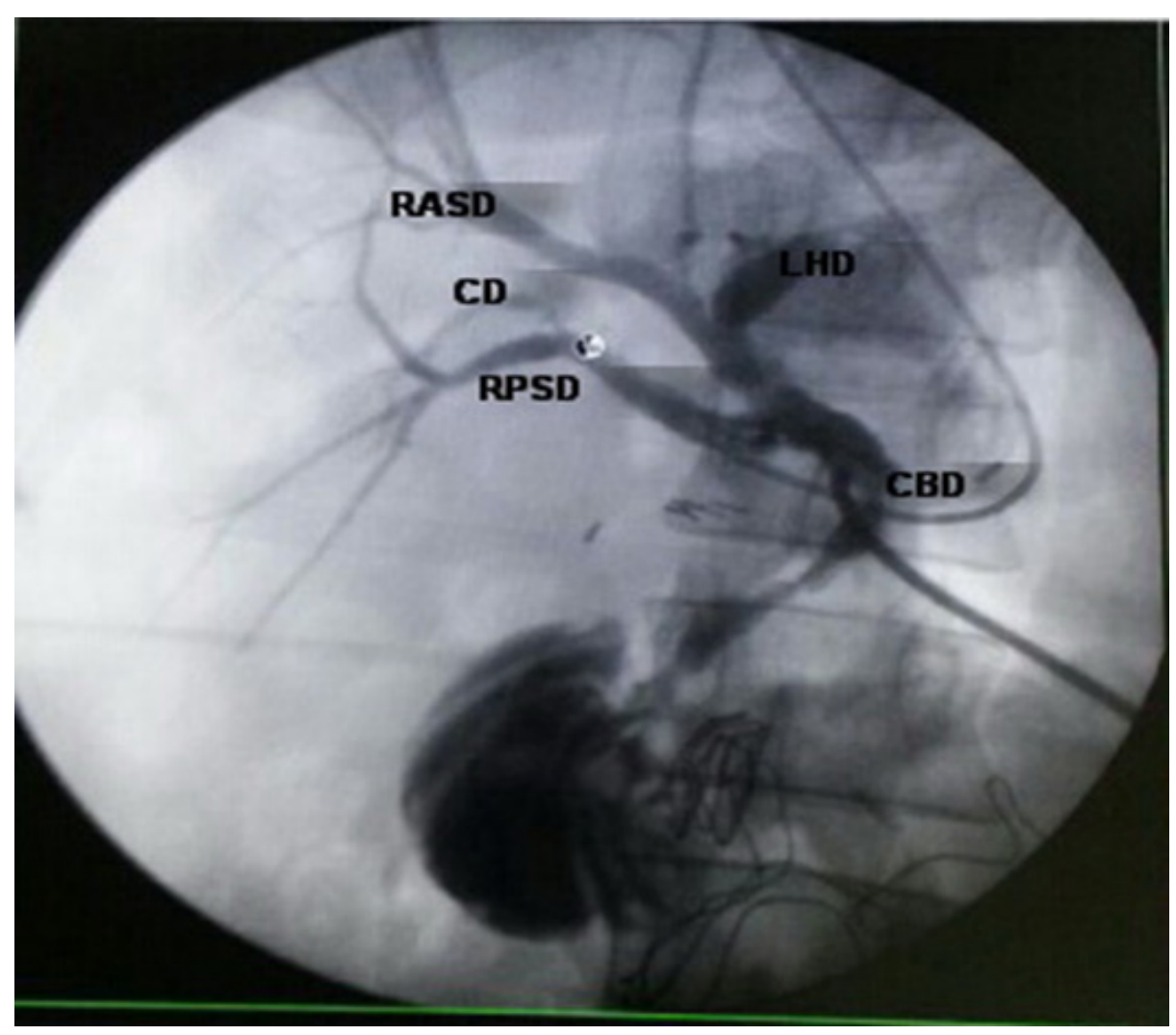

Figure 1: Cholangiogram revealed cystic duct (CD) drained into Right Posterior Segmental Duct (RPSD) RASD (Right Anterior Segmental Duct); LHD (left hepatic duct); CBD (Common bile duct)

\section{DISCUSSION}

Embryologically, the development of extra hepatic biliary system starts during the 4th week of foetal life. The hepatic diverticulum of foregut divides into 2 parts; pars cystica and pars hepatica. The hepatic ducts develop from pars hepatica. The gallbladder and cystic duct develop from pars cystica. During the development of pars cystica, at the junction of cystic and hepatic duct, the cells proliferate to form the common bile duct. Failure of this normal pattern of development leads to various anomalies of biliary ducts. ${ }^{1}$

The first discovery of cystohepatic duct variant was mentioned by Luschka in $1803 .{ }^{4}$ Kostov et al (2011) reported 32 biliary duct variations from more than 750 study samples over 10 years period. ${ }^{2}$ This variations are subdivided from the seven main anatomic variants which being introduced by Yoshida. The author divides the variant into 7 main types; Type ${ }^{1}$ - union of the right anterior segmental duct (RASD) and the right posterior segmental duct (RPSD) to form a right hepatic duct (RHD); Type 2 - union of the RASD, RPSD, and left hepatic duct (LHD) to form a triple confluence; Type 3-the RPSD draining directly into the LHD; Type 4 the RPSD draining into common hepatic duct (CHD); Type 5-union of the RPSD, left superior segmental duct (LSSD) and left inferior segmental duct (LISD) to form a trifurcation; Type 6 - union of RASD, RPSD and LSSD as a triple confluence and the LISD draining into the CHD; Type 7- he LISD draining into the CHD. ${ }^{3}$
Determination of biliary anatomy can be performed preoperatively by endoscopic retrograde cholangiography (ERCP), intraoperative cholangiography (IOC), Magnetic Resonance Cholangio Pancreaticography (MRCP), and Multi-detector row computed tomography cholangiography (CTC). ${ }^{3,5}$ Role of ERCP and MRCP are very important as preoperative planning can be made to avoid such injuries to the duct variants. In our report, weperformed intraoperative cholangiogram (IOC) because of dense adhesion after the Hartman's pouch to the cystohepatic junction.

We discovered the presence of right posterior segmental duct (RPSD) which drains the posterior sector of the liver. It was reported as one of the rare variants which accounts for only $0.5 \%$ to $2.8 \%$ (Yoshida type 4). . $^{2,5,6,7}$ The cystic duct drains directly to the right posterior segmental ducts (RPSD). Because of its proximity to the cystohepatic angle formed by the cystic duct laterally, the right hepatic lobe above, and the common hepatic duct medially, this accessory duct may be accidentally transected or ligated during cholecystectomy, and therefore, complications, such as the formation of a biliary fistula and biloma. ${ }^{2,8}$ When cholecystectomy is performed in patients with this variation, the cystic duct must be ligated between the gallbladder and the point at which the cystic duct joins the right posterior segmental duct ${ }^{9}$. 


\section{CONCLUSION}

Knowledge about normal anatomy of cystohepatic junction with careful attention to possible presence of congenital anatomical variance is crucial for surgeons in performing safe and successful hepatobiliary operations. It is advisable for the patient to undergo an evaluation of biliary tree anatomy before or during the surgery to avoid unintentional biliary duct injuries due to these anomalies.

\section{REFERENCES}

1. Aristotle S, Felicia C, Sakthivelavan S. An Unusual Variation of Extra Hepatic Biliary Ductal System: Hepaticocystic Duct. J Clin Diagn Res 2011; 5: 984-5.

2. Kostov DV, Kobakov GL. Six Rare Biliary Tract Anatomic Variations: Implications for Liver Surgery. Eurasian J Med 2011; 43: 67-72.

3. Lyu SY, Pan KT, Chu SY, Hsu MY, Chen CM, Hung CF, Tseng JH. Common and Rare Variants of the Biliary Tree: Magnetic Resonance Cholangiographic Findings and Clinical Implications. J Radiol Sci 2012; 37:59-67.

4. Devi T, Krishna P. The Study of Variations of ExtraHepatic Biliary Apparatus. IOSR JDMS 2013; 5:2531.

5. Ankouz A, Aittaleb K, Chakour K. Anatomical variations of the cystic duct. OA Anatomy, 2014; 2:14.

6. Mariolis-Sapsakos T, Kalles V, Papatheodorou K, Goutas N, Papapanagiotou I, Flessas I, Kaklamanos I, Arvanitis DL, Konstantinou E, Sgantzos MN. Anatomic Variations of the Right Hepatic Duct: Results and Surgical Implications froma Cadaveric Study. Anat Res Int 2012; Article ID 838179, 5.

7. Paul S, Jacinth JS, Muniappan V. Variations of the Extrahepatic Biliary Tract: Cadaveric Study. IOSR-JDMS 2013; 10:46-50.

8. Eduardo Cachoeira; Antonio Rivas, Carla Gabrielli. Anatomic Variations of Extrahepatic Bile Ducts and Evaluation of the Length of Ducts Composing the Cystohepatic Triangle. Int. J. Morphol. 2012; 30:279-283.

9. Jin Woo Choi, Tae Kyoung Kim, Kyoung Won Kim, Ah Young Kim, Pyo Nyun Kim, Hyun Kwon Ha, Moon-Gyu Lee. Anatomic Variation in Intrahepatic Bile Ducts: an Analysis of Intraoperative Cholangiograms in 300 Consecutive Donors for Living Donor Liver Transplantation. Korean J Radiol 2003; 4:85-90. 
 MJM
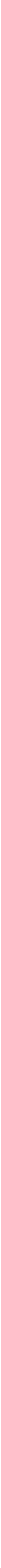
(1) 